\title{
The digital platform features for managing acceleration programs and project activities research
}

\author{
Maria Kamenskikh $^{1 *}$, Vladimir Postnikov ${ }^{1}$ \\ ${ }^{1}$ Economy and Management of Industrial Production, Associate professor, Perm National Research Polytechnic University, 29, \\ Komsomolsky av., Perm, 614990, Russia
}

\begin{abstract}
The article is devoted to the study of the essence of digital platforms and their main advantages. Digital platforms are now perceived as one of the most effective tools for conducting acceleration and project management programs. These digital platforms include such platforms that support projects, support work within teams, remind of important events and inform about other opportunities. The following advantages are highlighted: possible participants, availability of accelerators, availability of project showcases, project support, support for work within the team, event reminders, information about support systems, a platform engagement strategy. The main digital platforms for carrying out acceleration and project management programs, which are used in Russia, analyzed their main advantages for startups, investors, experts, ecosystem partners, infrastructure institutions and other stakeholders. There are digital platforms that provide the maximum number of services for program acceleration and project management. Opportunities for the development of digital platforms for conducting acceleration and project management programs have been identified. The research was carried out with the financial support of the Perm Government as part of a research project by the regional research group of agreement SED-26-12-10-5.
\end{abstract}

\section{Introduction}

Currently, the digital economy is actively developing. The introduction of information technologies allows more active development of interaction between inventors, investors, infrastructure institutions, small innovative enterprises, experts and other stakeholders in the framework of acceleration programs and project management. It is digital platforms that allow you to most efficiently implement these events.

Digital platforms are the most important objects of the information infrastructure. They appeared in the late 1990s, when networks, various platforms and ICTs began to form. Now the digital platforms increasingly perceived as a qualitatively new basis for the market structure, which contributes to the elimination of intermediaries and the expansion of modern business plans and models.

The growing competition in industries in both domestic and foreign markets, as well as the policies of countries aimed at creating legal and infrastructure conditions for building a digital economy, strengthens the position of companies. Today, one of the leaders in implementing digitalization strategies is the countries of the Asia-Pacific region. One of the main indicators is the number of companies (19\%) that launched digital transformation at the fundamental process levels. These include management, manufacturing, logistics, and marketing processes. Then the organizations of the countries of the Americas follow [2]. The integration of processes allows you to calculate the economic effect and efficiency both for the entire chain and for each of its participants separately. In addition, digital platforms are becoming a source for launching innovative processes.

\section{Research Background}

The digital platform (DP) is one of the significant tools that contribute to the transformation of traditional sectors of the economy and the transition to a digital economy. Digital platforms are "systems of mutually beneficial relations of a certain number of participants in the economic sphere of activity on the basis of algorithm, carried out in a single information environment. The use of the DP leads to a decrease in transaction expenses due to the use of a package of digital technologies for working with data and a change in the division of labor system" [7]. The definitions of digital platforms by different authors differ from each other. This is largely due to the relevance of the issue and the structured information. So, it is necessary to consider several approaches proposed by different sources (Table 1).

Among all the different definitions presented above, there is a common link in the understanding of digital platforms. The platform is nothing more than a business model. In another way, digital platforms are called multilateral, describing the concept of a bilateral market. The idea behind this concept is that the platform is an intermediary on which participating parties meet, offering each other value. In the basic example of a buyer seller, the first provides a solution to the consumer's problem in 
a commodity/service form, and the second transfers the form that closes his need [3].

Table 1. Approaches to the definition of "digital platform"

\begin{tabular}{|c|c|c|}
\hline No. & Definition & Author \\
\hline 1 & $\begin{array}{l}\text { The digital platform is a high-tech } \\
\text { business model that creates value } \\
\text { by facilitating exchanges between } \\
\text { two or more interdependent groups } \\
\text { of participants. }\end{array}$ & $\begin{array}{l}\text { Aalst, W., Hinz, O. } \\
\text { \& Weinhardt, C. } \\
\text { Big Digital } \\
\text { Platforms. }\end{array}$ \\
\hline 2 & $\begin{array}{l}\text { The digital platform is a system of } \\
\text { mutually beneficial relationships of a } \\
\text { significant number of independent } \\
\text { industry participants, carried out in a } \\
\text { single information environment, } \\
\text { leading to a reduction in transaction } \\
\text { expenses due to the use of a package } \\
\text { of digital data technologies and a } \\
\text { change in the division of labor } \\
\text { system on the basis of algorithm. }\end{array}$ & $\begin{array}{l}\text { Hein, } \\
\text { Schreieck, } \\
\text { Riasanow, T. et al. } \\
\text { Digital platform } \\
\text { ecosystems. }\end{array}$ \\
\hline 3 & $\begin{array}{l}\text { The digital platform is a high-tech } \\
\text { business model that creates profits } \\
\text { by exchanging between two or } \\
\text { more independent groups of } \\
\text { participants, the platform directly } \\
\text { brings together manufacturers and } \\
\text { consumers who are able to interact } \\
\text { without intermediaries. }\end{array}$ & $\begin{array}{l}\text { Nadkarni, S., } \\
\text { Prügl, R. Digital } \\
\text { transformation: a } \\
\text { review, synthesis } \\
\text { and opportunities } \\
\text { for future research. }\end{array}$ \\
\hline 4 & $\begin{array}{l}\text { The digital platform is an ecosystem } \\
\text { of solutions for customers or a level } \\
\text { of business model and customers } \\
\text { consider value. The necessary level } \\
\text { of products and services provided is } \\
\text { created through personalization, } \\
\text { customization, functionality, } \\
\text { logistics, integrated into the } \\
\text { ecosystem. }\end{array}$ & $\begin{array}{l}\text { Veisdal, J. The } \\
\text { dynamics of entry } \\
\text { for digital } \\
\text { platforms in two- } \\
\text { sided markets: a } \\
\text { multi-case study. }\end{array}$ \\
\hline
\end{tabular}

The study of digital platforms is a fairly new phenomenon in economics and management. The technical or functional elements that are most actively used both by project support platforms and in general by the digital market (Russian, world) include the following:

1. Project support.

2. Support for work within the team.

3. Event reminders.

4. Information about support systems.

5. Strategy for engaging participants on the platform.

It is on these elements that it is planned to conduct a study of existing platforms in the field of support for project management and acceleration programs.

The emergence and development of new generation digital technologies (in a different way, Industry 4.0) has become a defining trend in the formation of the modern world economy. Artificial intelligence, robotics, IoT, wireless/ 5G technologies, virtual and augmented reality, beacon beacons and other "end-to-end" technologies create tools that gradually enter the global business and provide performance. For example, according to technology experts, end-to-end technologies can increase productivity in enterprises by $40 \%$ [5].

Understanding the economic potential of technology for business, enterprises choose a focus on digitalization. We can say that a certain share of organizations has already entered the initial stage of digitalization: according to the research company - 34.4\% of respondents (sample - 300 companies) have developed a digital transformation strategy and are implementing it, and $26.6 \%$ plan to develop this direction in the future [4].

Each strategy can be based on different technologies. For example, as the mobile application market grows, multisectoral companies pick up this trend, develop or improve existing applications to optimize customer interaction processes. The technology of $5 \mathrm{G}$ can ensure the operation of mobile applications at a qualitatively new level. The business sees potential in this and is ready to invest: according to a Gartner study, $66 \%$ of companies plan to use $5 \mathrm{G}$ technology in working with their own applications [4].

Through the development of digital technologies, the market for online education, electronic commerce has formed, the market for online transport services is developing: "according to the official forecast of UBS by 2022 , the market capacity should grow by more than 8 times and amount to 1 trillion rubles" [10]. In turn, digital platforms act as intermediaries in new markets between customers and service providers, thanks to which the value chain (production, storage, transportation and exchange) is integrated into a single space directly with its participants. Building a platform-based business enables companies to reduce expenses, increase productivity, accelerate decision-making, and ensure a competitive market position.

\section{Materials and Methods}

Currently, a number of platforms operate in Russia and the world in the field of support for project management and acceleration programs. The entire set of platforms can be conditionally divided into two groups multifunctional and representing only one function. The latter include such platforms as:

- Information platforms for investors and startups (ICS - Information and communication system for supporting young innovators, PIPELINE, Unified Innovation Portal of the Samara Region RosInfra, Business Platform, Innovation Tatarstan, United Investors, SPARK);

- events of platforms (Calendarius, 2035.events, Leader ID 4ScienceTrello, Miro, Flowly);

- rating platforms (Yarating);

We consider the representatives of each group and describe their solutions in terms of basic parameters. Table 6 provides an analysis of existing platforms for project management support. A comparison of the basic parameters that are necessary for the successful operation of the platform shows that only one platform - the "Innovation Guide" - has implemented more than four functions.

The platforms Generations and BusinessChain implement four main parameters, while compared to the leader there is no support for work within the team. Other platforms are iGeneration and AXEL.online. We review existing platforms in project management and support and acceleration programs (Table 2). 
Table 2. Analysis of existing platforms in the field of project management and support and acceleration programs

\begin{tabular}{|c|c|c|c|c|c|c|c|c|}
\hline 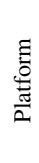 & 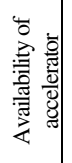 & 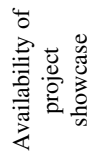 & 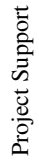 & 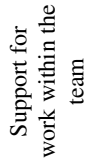 & 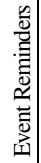 & 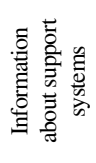 & 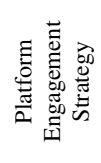 & $\stackrel{\Xi}{0}$ \\
\hline \multicolumn{9}{|c|}{ Russian } \\
\hline 1 & + & - & + & $+/-$ & + & - & + & 4,5 \\
\hline 2 & + & - & + & - & + & - & + & 4 \\
\hline 3 & + & + & + & - & - & - & + & 4 \\
\hline 4 & + & - & + & $+/-$ & - & - & - & 3,5 \\
\hline 5 & + & - & + & $+/-$ & + & - & - & 3,5 \\
\hline 6 & + & - & + & $+/-$ & - & - & + & 3,5 \\
\hline 7 & $+/-$ & - & + & + & - & - & - & 2,5 \\
\hline \multicolumn{9}{|c|}{ Foreign } \\
\hline 8 & + & + & + & $+/-$ & - & + & + & 5,5 \\
\hline 9 & + & + & + & $+/-$ & - & + & + & 5,5 \\
\hline 10 & + & + & + & - & - & + & + & 5 \\
\hline 11 & + & - & + & $+/-$ & - & - & $+/-$ & 4 \\
\hline
\end{tabular}

In the table 2 there are following platforms:

1. Electronic Acceleration Program Management System, Innovation Guide LLC;

2. GenerationS, RBC JSC;

3. BusinessChain, LLC IPI-Lab;

4. iGeneration, FSAEU HE NNSU;

5. AXEL.online based on the Venture Accelerator; of Tyumen State University;

6. Venture accelerator, Skolkovo;

7. CosmOdis, Education - Society Foundation;

8. BoomStartup, BoomStartup (USA);

9. Gust Accelerator Platform, RocketX (Great Britain);

10. AcceleratorApp, Lickability (USA);

11. Online platform for startups in Central Asia (Uzbekistan).

\section{Research Results}

CosmOdis has a sufficient number of functions, but it is aimed at school students and students, and not at startups. All other platforms show concentration on two functions. In addition to Russian, English-language platforms in the field of project management support were analyzed, such as BoomStartup, Gust Accelerator, AcceleratorApp, DealRoom, Extra Founder.

Their main functions are the presentation of startups for investors, as well as online training or information in the form of publication of training materials. All platforms are focused mainly on informing investors about startups, some have coverage of modern trends and platforms for discussing issues. A number of foreign platforms do not provide for regular maintenance, expertise or information about support systems. In addition, on all the platforms under consideration, with the exception of the Online Platform for Startups in Central Asia (Uzbekistan), there is no Russian language (mainly English is used, Spanish, Chinese, French, Arabic are also possible), which makes them inaccessible to the Russian wide audience.

Next, let's take a look at the benefits of using each platform to support project management from the perspective of the target audience and core functionality. Electronic Acceleration Program Management System, Innovation Guide LLC include: a. development and implementation of acceleration programs;

b. development and implementation of educational programs;

c. organizing and conducting educational events together with the necessary educational materials: master classes, conferences;

d. organization and conduct of project examination;

e. assistance in preparing projects for participation in third-party competitions, obtaining grant support;

f. investing in innovative startups with high growth potential.

GenerationS, RBC JSC includes:

1. Startups:

a. start of acceleration programs;

b. access to business infrastructure for piloting and launch

c. promotion of the project in the Russian and international markets.

2. Companies:

a. organization and implementation of acceleration programs;

b. developing an innovation strategy and conduct an innovative audit.

3. Experts:

a. access to the project base for examination.

4. Investors:

a. access to the project base of potentially commercialized projects for subsequent investment.

BusinessChain, LLC IPI-Lab has:

1. Startups:

a. start of acceleration programs.

2. Experts:

a. access to the project base for examination.

3. Investors:

a. access to the project base for investment. Projects are participants who have undergone acceleration.

4. Companies:

a. organization and implementation of corporate programs based on the platform;

b. access to projects that have been accelerated for later integration into the business infrastructure.

5. Accelerators:

a. organization and implementation of platformbased programs.

iGeneration, FSAEU HE NNSU involves:

1. Students:

a. development of the youth project environment of the university through organizing and conducting acceleration programs.

2. Business:

a. access to a project base for potentially interested companies.

3. Mentors and experts:

a. increased competence for mentors and the expert group.

AXEL.online based on the Venture Accelerator of Tyumen State University includes:

1. Startups:

a. access to acceleration and education programmes.

2. Investors: 
a. access to innovative development.

3. Experts:

a. access to the project base for examination.

CosmOdis, Education - Society Foundation involves:

a. access to an educational program on technological access to acceleration and education programmes.

b. entrepreneurship, engineering creativity;

c. access to the project presentation after passing project training, where representatives of schools, business and science from universities will meet.

Venture accelerator, Skolkovo includes:

1. Startups:

a. start of acceleration programs;

b. assistance in finding a team.

2. Companies:

a. organization and implementation of acceleration programs;

b. development of an innovation strategy and conduct an innovative audit.

3. Experts:

a. access to the project base for examination.

4. Investors:

a. access to the project base of potentially commercialized projects for subsequent investment.

BoomStartup, BoomStartup (USA) involves:

1. Startups:

a. provision of an individual acceleration plan;

b. initial evaluation of the project during the registration phase;

c. selection of mentors from the scientific and industrial sphere;

d. no competitive selection

2. Investors:

a. selection of five potentially successful projects.

3. Experts:

a. access to evaluation of various startup projects.

Gust Accelerator Platform, RocketX (Great Britain) has:

1. Startups:

a. access to the world's largest startup network;

b. possibility of using a set of tools and applications for the development of startups;

c. strong team in finance and jurisprudence.

2. Investors:

a. access to the base of startups and innovative projects.

3. Experts:

a. opportunity to work with projects from different countries.

AcceleratorApp, Lickability (USA) includes:

1. Startups:

a. access to an incubation/acceleration application;

b. constant communication with experts and mentors.

2. Investors:

a. access to the base of startups and innovative projects.

3. Experts:

a. access to the project base for examination.

Online platform for startups in Central Asia (Uzbekistan) involves:

1. Startups: a. programs for different groups of inventors and entrepreneurs.

2. Investors:

a. access to the project base for investment. Projects are participants who have undergone acceleration.

3. Experts:

a. access to the project base for examination.

So, according to the results of the analysis, Russian leaders - platforms in the field of project management are: electronic acceleration program management system, Innovation Guide LLC has 4.5 out of 7 points; GenerationS, JSC RBC and BusinessChain, LLC IPI-Lab has 4 out of 7 points.

\section{Discussions}

The comparison in the main parameters reflects that only four platforms - the Innovation Guide, Generations and Business Chain have three to five of the declared functions, one of them in part. All platforms, with the exception of Business Chain, have integrated the Support and Reminders function, as well as an activated strategy to attract participating parties to the site. The "Support" function implies the maintenance of participating parties and their support (organizational, technical, information) during acceleration programs.

In GenerationS, partial escort is practiced after the completion of the accelerator. The Reminders function takes the task of alerting: each party receives targeted notifications (directed exclusively to them). The presence of a strategy to attract participants to the platform was determined using the media center, content on social networks, as well as specialized programs for collecting advertisements on Internet resources.

The "Informations" feature is not available not only in the above platforms, but also in other participants. Support for working with participants within the team and additional functionality are partially present. A more detailed analysis of the project management platforms under consideration is provided in table 2 .

Based on the analysis, it can be concluded that the most quantitative and qualitative value propositions are formulated on two platforms - GenerationS and Business Chain ("IPI-Lab"). Quantification refers to the number of benefits described for each platform audience. Quality is interpreted in terms of meaning. However, to summarize, we will gradually move along the elements of the table. Positioning is used on each of the three platforms.

1. The Innovation Guide took an auditing position and defined it as a platform for innovative projects and entrepreneurs.

2. The positioning of GenerationS clearly reflects the niche in which they work - corporate innovation. They chose an audience-oriented approach. In this regard, all their offered services are built around the development of innovation in large companies.

3. Business Chain chose a different way of positioning: the platform combined the target benefit and focus on the audience: for whom this platform, as well as what result at the exit its participants will be able to get. 
First of all, the platform is designed to accelerate the growth of their capitalization. Startups receive investment and direct it to one of the "pain" areas, experts monetize competencies and form demand in the long term, accelerators launch the program with the support of platform owners, and investors expand investment portfolio and profit. In another way, the owners focused on profitability in the long run.

The next comparison parameter is services - what basic and additional services the platforms offer. The maximum number of characteristics is shown on the platform GenerationS, the smallest on the last. For startups on all platforms, 3 services are offered (taking into account open data): an educational module within the framework of the acceleration program, expertise and mentoring, consulting support. Company-based startup testing and access to innovative infrastructure are offered at the first two sites.

For projects, the Innovation Guide is more focused on the training component, as well as in general, putting it forward as a basis for business representatives. A broader proposal is the RVK platform: post-acceleration tracking in a closed alumni community, as well as a pilot launch in the company and PR support. The second audience is the company. For business, all platforms offer a service for organizing corporate programs, as well as narrower services related to training or scouting projects.

The "Guide to Innovation" focused on education through proposals for organizing master classes, conferences, video training, etc. GenerationS is focused on the practice and integration of startups into the company's activities, therefore it offers services in scouting, conducting strategic sessions, innovative audit and strategy development.

The third group is experts and mentors. For them, the main task is expert evaluation and interaction with startups and investors/companies, since sometimes they can receive a request for assessment, bypassing the course of acceleration. In the first platform, experts can increase competence with participation in educational programs (including international ones), as well as join the project team and continue to work with them.

At the second site, experts are involved in both the acceleration program and the development / implementation of educational modules. On the Business Chain services are exclusively basic. For investors, an open access service is integrated to the base of potentially commercialized/scalable projects at different stages of development. However, if access is provided through accelerators on the first two sites, then a separate base is used on the Business Chain. Projects are submitted to it, but they can be included by the owners of the platform, subject to prior scouting. In addition, the capabilities of the third platform involve investor cooperation and joint investment.

But the only unreached audience is ecosystem partners. The exception is GenerationS. Starting with the platform, they receive services to promote their projects to the markets, the participation of experts Generations at partner events, as well as the promotion of the partner and its events among the platform community.
On the list of services, the value proposition does not end, for a complete sheaf, the benefits are described - the advantages that the audience receives when "buying," using these services. The only platform on which the least number of benefits is indicated is the Innovation Guide. They are focused on startup projects. These are precisely the advantages on which each of the participants emphasizes: receiving investments, as well as "packaging the project".

From the point of view of marketing, the value propositions formulated by Business Chain more accurately reflect the need of the audience - faster obtaining investments, reducing the cost of finding independent solutions (including "packaging" the project). For companies, the value proposition focuses on increasing returns through access to high-potential projects. Third-party accelerators receive a funnel of projects and earnings.

GenerationS and Business Chain for experts with the help of developed services provide an influx of new customers. But then the first platform focuses on increasing competence, and the second on increasing demand through increasing recognition. Accordingly, the investor in the long run makes a profit and nurtures the investment portfolio. However, none of the platforms presented when promoting targeted services for companies and a supporter of accelerators have not put forward as a distinctive advantage for companies and third-party accelerators - reducing the cost of organizing and implementing acceleration programs.

The question arises: why is not the emphasis on startup projects, investors or experts? The fact is that companies and third-party accelerators, and other representatives of the innovative infrastructure are customers of platform services. Without their request, one or another program will not be formed - corporate accelerator, intracorporate, educational module, etc. Since, if there is an event, promotion campaigns will be launched in the future to involve the next participating platform groups startups, experts and investors. Therefore, the primary audience for platform owners is representatives of business and innovative infrastructure.

The next comparison parameter for innovative project support platforms is the source of monetization. In Generations for teams, participation is free, business, acting as a customer of corporate programs, project scouting or innovative audit, is a source of funding. Interaction with ecosystem partners takes place at the level of barter, mutual exchange of services - assistance in organization, marketing, joint launch of events. For experts, the platform becomes a source of earnings, but participation in educational programs is paid. Participation of investors in the platform programs can take place at the invitation of the organizers or by preliminary selection (the investor applies for participation). In general, the interaction process on the platform is free for him. The next platform is the Innovation Guide. Similar to the previous experience on this platform, funding is provided by service customers representatives of infrastructure and business. Other sources of monetization on the platform are not involved, as for the Business Chain platform. 


\section{Conclusions and Further Research}

So, the study showed that digital platforms have a number of advantages in managing acceleration programs and projects. Next, it is rational to consider the features of the development of a digital platform. Development of a digital project support platform (acceleration, tracking, packaging, incubation), management of acceleration programs (information campaign, acceptance of applications, expertise, acceleration), information about support programs (grants, subsidies, competitions). The goal is to improve the system of attraction to technological entrepreneurship, the development of the information space of innovation support systems, the development of tools for managing acceleration programs and project activities. In the initial phase, the platform will assume the task of organizing and conducting acceleration programs and supporting innovative projects within its framework. The developed platform will allow you to manage and accompany innovative and technological projects as part of acceleration programs and competitions, including registration, filling out a personal account, filling out a project profile, correspondence examination of the project, examination of projects by video link, conducting educational programs, tracking projects, consulting support, communication chains, analytics. Subsequently, as the platform develops, other services can be added that satisfy the requests of the involved groups. The analytical part of the research made it possible to form the competitive advantages of the platform - services that will be directed to each of the involved parties:

- availability of personal rooms for all platform participants;

- possibility of submitting projects for events;

- maintenance of work within the project team;

- project moderation and examination;

- carrying out the acceleration program;

- familiarization with the accelerator community, as well as access to useful contacts through experts, coaches and mentors;

- information on support systems;

- system involvement of participants on the platform;

- convenient interface.

The platform begins with registration. When performing registration actions (filling in the email field and password), the participant enters personal account, where it reflects one's role: administrator; moderator; user (startup); Customer; investor; expert; tracker/mentor. In the personal account, the participating parties will have opportunities - functions that they can use to perform certain actions.

\section{References}

1. W. Aalst, O. Hinz, C. Weinhardt Bus Inf Syst Eng 61, 645-648 (2019). https://doi.org/10.1007/s12599-01900618-y
2. F. Aulkemeier, M.E. Iacob, J. van Hillegersberg Electron Markets 29, 597-608

(2019). https://doi.org/10.1007

3. E.R. Banalieva, C. Dhanaraj J Int Bus Stud 50, 1372-1387 (2019). https://doi.org/10.1057/s41267-01900243-7

4. Z. Deng, P.W. Liesch, Z. Wang J Int Bus Stud (to be published). https://doi.org/10.1057/s41267-02100401-w

5. M. Drewel, L. Özcan, J. Gausemeier, et al. J Knowl Econ (to be published). https://doi.org/10.1007/s13132-021$\underline{00772-3}$

6. A. Hein, M. Schreieck, T. Riasanow, et al. Electron Markets 30, 87-98 (2020). https://doi.org/10.1007/s12525-01900377-4

7. A. Hevner, O. Malgonde, Electron Markets 29, 407-421 (2019). https://doi.org/10.1007/s12525-01900334-1

8. S. Nadkarni, R. Prügl, Manag Rev Q 19, 230-237 (2020). https://doi.org/10.1007/s11301-020$\underline{\text { 00185-7 }}$

9. M. Reuver, C. Sørensen, R.C. Basole, J Inf Technol 33, 124-135 (2018). https://doi.org/10.1057/s41265-0160033-3

10. A.K. Song Small Bus Econ 53, 569-590 (2019).

https://doi.org/10.1007/s11187-01900232-y

11. J. Stayton, V. Mangematin, J Technol Transf 44, 1163-1187 (2019). https://doi.org/10.1007/s10961-0179646-0

12. F. Sussan, Z.J. Acs, Small Bus Econ 49, $55-73$

(2017). https://doi.org/10.1007/s11187-017$\underline{9867-5}$

13. D.J. Teece, G. Linden J Org Design 6, 8 (2017).

https://doi.org/10.1186/s41469-0170018-x

14. J. Veisdal Electron Markets 30, 539556

(2020). 
https://doi.org/10.1007/s12525-020-

00409-4

15.F. Zhang, Z. Gao, Q. Ye, Aut. Control

Comp. Sci. 49, 373-379 (2015).

https://doi.org/10.3103/S014641161

$\underline{5060127}$ 